\title{
On the Tai Chi Spatial Pattern in Ursula Le Guin’s The Left Hand of Darkness
}

\author{
ZHANG Na \\ Guangdong University of Foreign Studies, Guangzhou, China \\ Guangdong Science Center, Guangzhou, China
}

\begin{abstract}
On the basis of Gabriel Zoran's theory of spatial pattern, particularly the 3 levels of world reconstruction, the pattern of narrative space in Ursula Le Guin's The Left Hand of Darkness is figured out. A spatial pattern of Tai Chi diagram is established on the textual level, the chronotopic level and the topographical level simultaneously. To demonstrate the validity of this Tai Chi spatial pattern, the stylistic feature of "shfgrethor" is analyzed in accordance with the Tai Chi spatial pattern, thereby proves the pattern's reliability. As an effect, this Tai Chi spatial pattern functions as Le Guin's fitting shape of carrier bag in science fiction containing both mythology and realist elements into a cyclic narrative.
\end{abstract}

Keywords: chronotype, Tai Chi spatial pattern, narrative space, carrier bag

\section{Introduction}

Fictions, as well as other texts, are traditionally believed astemporal works of art, since in the Western philosophical tradition, being is much more frequently associated with time than space, for instance, Heidegger in his Being and Time (1927) indicates that how the understanding of being is essentially temporal (Blattner, 2006, p. 14). Einstein's term chronotype attributes time to the fourth dimension of space, thus combining space and time together to an unprecedented level. Mikhail Bakhtin introduces Einstein's chronotype into literary criticism to signify the entire complex of space and time. Spatial pattern isscripted by Gabriel Zoran on the basis of previous literature scholars' consideration on space in texts, primarily Mikhail Bakhtin's chronotype (1937) and Joseph Frank's spatial form (1945). Moreover, Zoran is also enlightened by the 1970s postmodern culturalists Michael Foucault, Henri Lefebvre, especially Julia Kristeva who focuses on ideology and power relations, thus to embed his analysis of spatial pattern into both paradigms of classical and post-classical narratology. In the light of Zoran's spatial pattern, Ursula Le Guin's science fiction masterpiece, The Left Hand of Darkness (1969) (abbreviated as LHD below) can be more thoroughly studied from a spatial angle.

The spatial pattern is metaphoric or symbolic in essence, which can be revealed only after reading repetitively. Fictions with a spatial form is not in a simple chronological development, but combines several lines of narratives, whose plots can be integrated into an abstract architectural image, such as the spatial form of church

ZHANG Na, Ph.D. Candidate in $20^{\text {th }}$ Century Anglophone Literature, Guangdong University of Foreign Studies; Guangdong Science Center. 
in Marcel Proust's In Search of Lost Time (1922), labyrinth in Jorge Luis Borges' The Garden of Forking Paths (1941), isolated and closed circle in García Márquez’s One Hundred Years of Solitude (1971) (LONG, 2014, pp. 150-157). It is worthwhile to mention that not all fictions contain a spatial pattern, on the contrary, relatively few have such an implicit architecture, though Joseph Frank argues that spatial form is a character of modern literature to deliberately disrupt the traditional chronological linear plot anchoring on time (Frank, 1945).

LHD contains 20 chapters, with narrator shifting between the envoy Genly Ai from the Ekumen of Known Worlds and the (former) head minister Estraven to the King of Karhide on the planet of Gethen in larger part of the text except for 6 chapters, (chapters 2, 4, 7, 9, 12, 17). These 6 chapters scatter among the chronological narrative of Genly Ai's adventure in Gethen, mainly accompanied by Estraven, for his mission to enlist the two Gethenian countries Karhide and Orgoreyn to join the Ekumen. Among these 6 chapters, chapter 7, narrated by a woman investigator of the first Ekumenical landing party on Gethen, in a form of scientific observation report/experiment recording, evidently differs from other 5 chapters of mythological or legendary narrative, thus can be put aside for the convenience. From Zoran's 3 levels of structuring of spatial pattern: the textual level, the chronotopic level and the topographical level, the production of LHD space can be analyzed accordingly.

\section{Curved Temporality and LHD's Discipline of Presence}

The narrative spot can be viewed as a point along a reversed sigmoidal curvetraveling through the interior of a circular starting from the upper end of a diameter to the bottom end. The area shaped by a line perpendicular to the diameter through the narrative spot with the the upper circumference the narrative spot leaves behind represents the space produced on the textual level. It is apparent that this space is divided into 2 unequal parts, both with the tendency of enlargement, but one area is bigger than another. Compared to the alternative narration of reality (chapters $1,3,5,6,8,10,11,13,14,15,16,18,19,20)$ and mythological/legendary narration (chapters 2, 4, 9, 12, 17), the larger sub-space represents the reality, while the smaller but gradually expanding one represents the textual space of legends, and later slides into the space of myths. In other words, the two fish-shaped areas divided by the curve are representations of reality space and memory/history space respectively, the latter is particularly intensified by the shift from the genre of legends (chapter 2, 4, 9) to the more remote and esoteric myths (chapters 12,17) ingrained firmly to the deeper layer of the "collective unconsciousness" on the planet of Gethen. For instance, chapter 2 is a North Karhidish hearth-tale, chapter 4 is an East Karhidish Arabian Nights-like folklore,chapter 9 is an East Karhidish tale, and chapter 12 is a North Orgoreyn Yomesh Canon (Bible styled) story, considering the words of directions (North - East), the movement of narrative spot is indeed from North to East along the sigmoidal curve from up to bottom.

Chapters 2, 4, 9, 12, 17 of legendary/mythological narrative is distinctively in Le Guin's style constructing a highly reliable planet with myths/legends serving as the mass mind which situates at the core of the cultural location, and functions to shape the surface level of narration. In this sense, the 5 legends/myths constitute, in Greimas' term, the deep narrative structure or the narrative grammar, where Greimas argues the narrativity is situated (Greimas \& Porter, 1977).

Le Guin explains the relations between unconsciousness and shadow/darkness in her nonfiction work. On the title of LHD, Le Guin once said that "We like to think we live in daylight, but half of the world is always dark; and fantasy, like poetry, speaks the language of the night” (1992) and proposed that science fiction is a modern 
fantasy. Le Guin highly values the sphere of shadow and regards a space voyage, in essence, as a way through somebody else psychic abysses,

....in order to reach the others, the artist goes into himself. Using reason, he deliberately enters the irrational. The farther he goes into himself, the closer he comes to the other... A rational perception has all get down into the unconscious, and ferment in the darkness, and work slowly back into the light. (1992)

Compared with reality, the space of legend/myth, memory/history is shadowed darkness, which remains opaque and shapes the the contour of reality in an enigmatic and mysterious way.

In this way, the narrative of LHD strides both forwardly and backwardly, to the future and to the past, as the time indicators of those 5 legendary/mythical narratives from past to ancient and even prehistorical (chapter 2 is recorded during the reign of Argaven VII, chapter 4 is recorded on 93/1492, the same with reality time, happening date unknown, chapter 9 is narrated before the days of King Argaven I, chapter 12 is composed about 900 years ago, chapter 17 originates prehistorically). The chronological progress of time is thus fragmented. Time is no longer a linear extension, but a curved one with both dimensions of past and future. Such an arrangement of narrative time highly aligns with the LHD view of time- the discipline of presence, as well as Le Guin's view on the time dimension of science fiction, in her word, “The purpose of a thought-experiment, as the term was used by Schrodinger and other physicists, is not to predict the future ... but to describe reality, the present world. Science fiction is not predictive; it is descriptive” (1969, p. 3). Thus on the nature of science fiction, Le Guin breaks down the science fiction genre stereotype to stretch its time and space, mostly by compressing the "being to the death" adventure and "can not do anything for the deceased" epic into a narrative of presence.

Throughout LHD’s narrative, there are mainly 4 quasi-asymmetrical places addressing the perception of time on the planet of Gethen, in chapter 1 and Appendix after chapter 20, as well as in chapter 5 and chapter 12 , with the former pair about time on Gethen (composed by nation of Karhide and nation of Orgoreyn), while the latter pair about time in Karhide and Orgoreyn respectively. At the beginning of chapter 1, time calculation method is described by the narrator Genly Ai, "It is always the Year One here. Only the dating of every past and future year changes each New Year's Day, as one counts backwards or forwards from the unitary Now” (Le Guin 1969, p. 5). After the end of the last chapter, Le Guin adds an appendix named "The Gethenian Calendar and Clock”, where itexplains again the Year One,

In Karhide/Orgoreyn years are not numbered consecutively from a base year forward to the present; the base year is the current year. Every New Years Day the year just past becomes the year "one-ago," and every past date is increased by one. The future is similarly counted, next year being the year "one-to-come," until it turn becomes the Year One. (Le Guin, 1969, p. 147)

Though one self-unconscious, the other self-conscious, the two religionson Gethen, Handdara and Yomesh, view time similarly with an ultimate emphasis on presence or the center oftime. In "Chapter 5. Domestication of Hunch”, the narrator Genly Ai goes deeper into Karhide to see foretellers of the Handdara which is Karhideian religion with a mythical discipline, Handdara discipline of Presence. There he meets Faxe, the weaver. After a ritual through a "spiderweb", a web of power, with Faxethe weaver situating at the center, Ai's question is answered. Although a foreteller acquires the capacity to answer,what foretelling does is to "exhibit the perfect 
uselessness of knowing the answer to the wrong question” (Le Guin, 1969, p. 38). Chapter 12 is a Bible styled myth describing the view of time in Yomesh religion of Orgoreyn, God-like figure Meshe is the Center of Time, every man is in the Center of Time, thus are the pupils of his Eye, "there is neither source nor end, for all things are in the Center of Time ... One center, one seeing, one law, one light” (Le Guin, 1969, p. 82).

The sigmoidal curve of time stretches farthest to the future in chapter 5 where Genly Ai asks Faxe, the weaver to predicate the future with a positive answer, and farthest to the past in chapter 17 where the genesis of mankind is explained in a prehistorical myth, but on the whole, a balance is reached between past and future, thus an eternal presence is achieved in this textual level of spatial pattern. Moreover, the balance of past and future also combines Mikhail Bakhtin and Goerg Lukacs' nostalgic “can not do anything for the deceased” epic genre and future-oriented "the being to the death” novel genre (1981), also vividly expresses the thematic poem's lines "Two are one, life and death, lying together ... like the end and the way” (Le Guin, 1969, p. 115) in an imagery spatial pattern.

\section{Chronotopic Space of Dual Places}

The second level of Zoran's reconstructed world is the chronotopic level. The very term of chronotope is introduced to literary criticism by Mikhail Bakhtin, in The Dialogic Imagination, Bakhtin defines the concept of chronotope.

We will give the name chronotope (literally, "time space") to the intrinsic connectedness of temporal and spatial relationships that are artistically expressed in literature. This term [space-time] is employed in mathematics, and was introduced as part of Einstein's Theory of Relativity ... we are borrowing it for literary criticism almost as a metaphor (almost, but not entirely). What counts for us is the fact that it expresses the inseparability of space and time (time as the fourth dimension of space). (Bakhtin, 1981)

Zoran implants Bakhtin's concept of chronotope as the second level of world reconstruction. On this chronotopic level, according to Zoran, the reconstructed world is already independent of verbal arrangement of the text, but is still dependent on the plot. On this level, the effect on the structure/organization of space is produced by chronotype, particularly the movement, the action of the narrative (Zoran, 1984). Most characters including Argaven the King and Faxe the Weaver in Karhide are at rest, restricted to a state of being bound to a given spatial context both geographically and mentally, as Argaven XV's fear of new ways and new ideas, using fear to rule his people to confine his people in a mental space of fear, and Faxe the Weaver refuses to learn mindspeech from Genly Ai, against progress and change. However, in LHD, there are two characters of motion, Genly Ai and Estrven, both possess the ability to cut himself off from spatial context and switch over to different contexts.

The whole story starts from Genly Ai's motion from Ekumen the Known to the Planet of Gethen, developed by Estraven and Genly Ai's relative motion to each other, and ends shortly after Estraven's rest from death. It is more obviously judged from titles of chapters, most of which are named by places or motion, such as "Chapter 1. A Parade in Erhenrang”, "Chapter 2. The Place Inside the Blizzard”, "Chapter 6. One Way into Orgoreyn”, "Chapter 8. Another Way into Orgoreyn”, "Chapter 10. Conversation in Mishnory”, "Chapter 11. Soliloquies in Mishnory”, “Chapter 13. Down on the Farm”, “Chapter 14. The Escape”, “Chapter 15. To the Ice”, “Chapter 16. Between Drummer and Dremegole”, “Chapter 18. On the Ice”, “Chapter 19. Homecoming”. Genly Ai and 
Estraven moves in the country of Karhide and Orgoreyn, the former is characterized as incalculable, insane, involuntary, introvert,indirect and slow, with a sense of "always being under the shadow of something high and gloomy” (Le Guin, 1969, p. 28) as manifested in its architecture of red keystone of arches made from human bones and human blood, as well as sky-reaching towers and palaces, while the latter is prominently associated with comfort and openness. Thus these two countries can be represented by the sphere of darkness and light logically.

Zoran concerns the synchronic and diachronic relationships on chronotopic level of spatial pattern. In the synchronic relationships he focuses on motion and rest,whereas in the diachronic relationships, heemphasizes directions, axes and powers. As stated in the last section, time composed by narrative spots is represented as a reversed sigmoidal curve, this curve also demonstrates the axes of movement, with the light sphere as the place of Orgoreyn and the dark sphere as the place of Karhide, thus the tangent of this motion curve becomes the indicator of motion direction. Both Genly Ai and Estraven undertake the axes from Karhide to Orgoreyn, and back to Karhide, that is from sphere of darkness to sphere of light, and back to sphere of darkness as indicted by the tangent line of sigmoidal curve of time and path.

Coincidentally, their motion paths are almost the same despite the initial departure from each other, as Estraven is exiled first and arrives at Orgoreyn earlier than Genly Ai, meanwhile before leaving Karhide, Genly Ai goes deeper to the Fastness place in Karhide to learn its religion of foretelling, soon after their meeting each other in Orgoreyn, Genly Ai is arrested and sent to the concentration camp-like Pulefen Farm into the depth of Orgoreyn,later rescued by Estraven, and both of them embarks on a homecoming journey full of trials and tribulations to Karhide. As Genly Ai mentions, "I was born to live in exile, it appeared, and my one way home was by way of dying” (Le Guin, 1969, p. 28). What ensues homecoming is Estraven's death. Estraven accompanied Genly Ai's travel on the alien planet of Gethen for the majority of time, except for Ai's misunderstanding of Estraven and Ai's last wandering after Estraven's demise, which is also represented in the chronotopic spatial pattern, as the first three chapters and the last three chapters are narrated by Genly Ai, while other interval chapters (except legendary/mythical narrative chapters) are narrated by Genly Ai and Estraven in sequence, depicting their mutual chronotope, the same time-space, from Genly Ai's and Estraven's perspectives respectively, such as "Chapter 10. Conversation in Mishnory" narrated by Genly Ai verses "Chapter 11. Soliloquies in Mishnory" narrated by Estraven, "Chapter 13. Down on the Farm” narrated by Genly Ai verses "Chapter 14. The Escape" narrated by Estraven, and "Chapter 15. To the Ice" narrated by Genly Ai verses "Chapter 16. Between Drummer and Dremegole” narrated by Estraven. More than natural places of the two countries, Karhide and Orgoreyn, Genly Ai and Estraven are actually moving back and forth along axes with definite directions in the field of powers (Zoran, 1984).

The turning point occurs at the center of the circle, which is the question of sex in chapter 7 , a scientific investigation recorded by a woman investigator from the first Ekumenical landing party on Gethen. Before chapter 7, in "Chapter 6. One Way into Orgoreyn”, Genly Ai sets off west to leave Karhide and turns back no more, in the small town of Kuseben, he meets his kermmer (lover) Ashe. After chapter 7, in "Chapter 8. Another Way in to Orgoreyn”, Genly Ai gets the identification paper and is able to go to Orgoreyn, the evening before Ai's leaving Karhide, Estraven's kemmer (lover) Foreth visits him. Such an arrangement of movement indicates that only by objective and scientific perception of the problem of sex on Gethen, can Genly Ai moves smoothly 
along his path, otherwise, he is not capable of moving any further. Setting the question of sex at the center of spatial pattern signifies Le Guin's central concern on composing LHD. In 1960s, the second wave feminist movement begins to gain momentum, the real difference between men and women is the elemental question for Le Guin and other feminist thinkers of that time. Her philosophical "thought experiment” in LHD is inspired thereby.

\section{Gestalt of Tai Chi Diagram as A Topographical Map}

In the two sections above, the spatial pattern of a circle with a curve passing throughis established, which divides the circle into two fish-shaped spaces, one light, one dark, representing future oriented "the living to the dead" narrative of reality and past-oriented "can not do anything for the deceased" narrative of legends, folklore and myths on textual level, as well as places of two countries of Orgoreyn and Karhide on the chronotopic level. Such a spatial pattern is further developed to a gestalt of Tai Chi diagram, with the black point in the light fish representing Estraven, and the white point in the dark fish representing Genly Ai. Estraven is described as a being of darkness, elusive and hard to penetrate, whereas Genly Ai, an isolated envoy on the alien world of Gethen, is always bright against his dark and opaque surroundings wherever he goes.

In the topographical space of LHD, Karhide and Orgoreyn are two places, as well as adventure and epic are two genres, and there is a possibility of moving from one to the other. But the actual direction of movement is determined by the chronotopic structure; thus one place/genre is defined as the point of departure, another as the target, and others as stations on the way, deviations,etc. As the narrative spot moving along the curve from the top to the bottom, there first appears the black point in the light fish, i.e. Estraven in the country of Orgoreyn, waiting for the emergence of the white point in dark fish, i.e. Genly Ai. No doubt that Genly Ai exists in the narrative from the beginning to the end, nevertheless his misunderstanding in early period prevents him to see Estraven as an equal counterpart, despite Estraven's constant support for him, no matter under what circumstances. What Estraven as the black point waits is the mutual understanding and recognition between he and Genly Ai, which truly occurs during their tortured travel back to Karhide, especially after their climax exchange of foretelling and mindspeech in Estraven's kemmer period, as Estraven identifies Genly Ai as his lost brother Arek who has been dead fourteen years ago. Their mutual exchange does not take the form of bodily intercourse, but by the means of communication both consciously during the harsh journey and unconsciously in dreams and mindspeeches, which can also be illustrated by the topographical map of Tai Chi diagram, as the two points are identical to each other, each as the other's reflection, but communicate in a distance, separated by the curve of temporarily and axes. Although Genly Ai is bewildered by the biological shock on Gethen, as people there are for the most time hermaphroditic, containing the potentialities of both sexes of female and male, the sexual shell often disappears and over time, the inner, sexless personality emerges. Genly Ai and Estraven identified with each other on such a sexless personality dimension and become a duality of existence, after which their boundary becomes blurred and melted away, it is hard to distinguish one's speech from the other, as if Genly Ai and Estraven are integrated into an inseparable unity.

According to Zoran, the topographic level is on the highest level of reconstruction, the world is perceived as existing for itself, with its own "natural" structure, cut off entirely from any structure imposed by the verbal text and the plot, whose structure may be conceived as a kind of map based on elements from the entire text, including 
all its components, in addition, the map has patterns which refer not to the location of things, but rather to their quality and the map is based on a series of opposition (Zoran, 1984). The topographical map of Tai Chi contains light and dark fish-shaped sub-spaces drawn from both verbal text and the plot, and can be used as a meta-structure to explain most elements from the narrative discourse and stories. More explicitly, this topographical map is mentioned briefly after the climax of the story, after the mutual identification between Genly Ai and Estraven, Ai clearly describes the Tai Chi diagram,

I drew the double curve in within the circle, and blacked with yin half of the symbol... It is yin and yang. Light is the left hand of darkness ... how did it go? Light, dark. Fear, courage. Cold, warmth. Female, male. It is yourself, Therem. Both and one. A shadow on snow. (Le Guin, 1969, p. 130)

The establishment of such a topographical map is based on both the textual and chronotopic spatial pattern, and the Tai Chi diagram as a spatial pattern loomson three levels almost simultaneously, such as Zoran argues,

...the reader does not begin at the textual level and then pass on to the others, or vice versa; rather, he is continually moving back and forth among the three levels and, moreover, he perceives them at once without being able to separate them. (1984)

The spatial pattern of Tai Chi diagram on textual, chronotopic and topographical levels is the best structure to express LHD's theme: dualism in oppositions of male and female, Karhide and Orgoreyn, past and future etc. should be transformed into the relation of Yang and Yin in Taoism, like left hand and right hand, one is changeable into the other, both are one, as conveyed by the lines below,

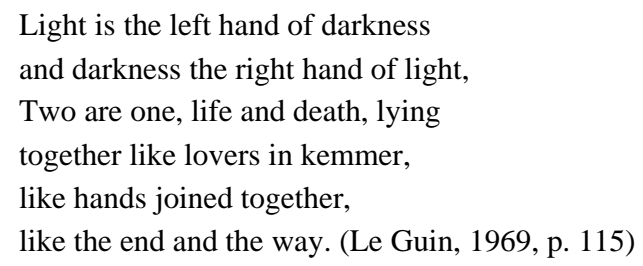

\section{Verification of the Tai Chi Spatial Pattern}

As Zoran suggested, such a topographical map should have the function to explain other elements in the text, though not exhaustively. Now let's judge its appropriateness by means of its power of textual explanation. There is a conspicuous textual feature, the creation of new words. To demonstrate high credibility of the truth of LHD's fictional narrative, on stylistic level, Le Guin creates a system of language on Gethen, as well as a Gethenian Calendar and Clock corresponding to phrase of the moon. The meaning of Gethen language is veiled, which can only be revealed upon Ekumenian envoy Genly Ai's acquisition with his limited knowledge on Gethen. A few of Gethenian words remain opaque beyond Genly Ai’s understanding, such as "shifgrethor” in Karhidish which is used with the highest frequency in discourse related to Estraven, Karhidish King Argaven and the nationality of Karhide, totally appears 36 times in LHD.

As a noun, it goes after two verbs for the most of the time in phrases like "play shifgrethor" and "waive shifgrethor”, with opposite meaning. It first appears during Estraven's equivocal conversation with Genly Ai in the depth of the former's prime minister house on the evening before his forced exile by King Argaven. Upon Estraven's pause in answer, the narrator Genly Ai thought himself as an inept and undefended alien who will 
never understand the foundations of power and the workings of government in Karhide, and attributes his confused confrontation all to "a matter of shifgrethor-prestige, face, place, the pride-relationship, the untranslatable and all-important principle of social authority in Karhide and all civilizations of Gethen. And if it was I would not understand it” (Le Guin, 1969, p. 11). Genly Ai’s understanding on "shifgrethor” is based on his experience and embeds it into his vocabulary, later in Ai and Estraven's journey escaping from hellish Pulefen Farm in Orgoreyn, returning to Karhide, Estraven enters the kemmer period, and Ai asks Estraven, "I've made some mistake in shifgrethor. I'm sorry; I can't learn. I've never even really understood the meaning of the word." Estraven replied, "Shifgrethor? It comes from an old word for shadow" (Le Guin, 1969, p. 120). In kemmer, through exchange, partners reach a full understanding of each other, long standing misunderstanding melts away, though no bodily intercourse between them, through mutual learning (Genly Ai's learning of Karhidish foretelling and Estraven's learning of Ekumenian mindspeech), their minds communicate effectively.

In this sense, "shfgrethor" and shadow, the unknown and the known, the overt and the hidden, all relations of dualism can be demonstrated by the Yin and Yang diagram. Moreover, there is a coincidence of the number 36, in “Chapter 17. An Orgota Creation Myth”, the house of flesh is built up by 36 brothers' corpses killed by the first awakening man Edondurath, the architecture of flesh also occurs in chapter 1, in the city of Erhenrang in Karhide, Argaven XV sets to work methodologically to mortar the keystone of Old Bridges' arches which is made up by human bones blood, because without the bloodbond the arch would fall. It means that all the human bones and blood, corpses of brothers are shadows ("shfgrethor"), thus generations originate from the house of flesh, will all live with shadows and threatened by death, which also explains the enduring omnipresence of fear in Karhide.

\section{Conclusion}

On the basis of the analysis above, a spatial pattern as Tai Chi diagram is figured out on Zoran's textual, chronotypic and topographical levels respectively, which works effectively as in the illustration of textual elements, the stylistic feature of Le Guin's invented word "shfgrethor”. Thus Le Guin's LHD proves to contain such an exquisite Tai Chi spatial pattern which is highly compatible with LHD's theme of Taoism, whose narrative structure and narrative content combine to an unprecedentedly ideal degree of integration.

In Le Guin's nonfiction Dancing at the Edge of the World (1990), she puts forward the carrier bad theory of fiction. Differ with the arrow/spear "proper shape of narrative", she argues that the fitting shape of the novel might be a sack/bag, since that “a book holds words. Words hold things. They bear meanings” (Le Guin, 1990, p. 169). In this way, Le Guin redefines technology and science as primarily cultural carrier bag, rather than weapon of domination like linear, progressive, time's arrow mode, and as a pleasant effect, "science fiction can be seen as a far less rigid, narrow field, not necessarily Promethean or apocalyptic at all, and in fact less a mythology genre than a realist one” (Le Guin, 1990, p. 170). The Tai Chi spatial pattern can serve as such a carrier bag, a container, inside which each element can be transformed from one polar to its opposite, thus the dualism mode no longer exists. Moreover, the overall shape of this Tai Chi spatial pattern as a circle subverts the traditional linear narrative of science fiction, expanding the genre of science fiction to contain both elements of mythology and realist novel, which is Le Guin's contribution to the narrative of science fiction. 


\section{References}

Bakhtin, M. (1981). Forms of time and of the chronotope in the novel: Notes towards a historical poetics. In C. Emerson and M. Holquist (Trans.), The dialogic imagination: Four essays. Austin: University of Texas Press.

Blattner, W. (2006). Heidegger's Being and Time a reader's guide. London \& New York: Continuum International Publishing Group.

Frank, J. (1945). Spatial form in modern literature: An essay in three parts. The Sewanee Review, 53(3), 433-456. Baltimore: Johns Hopkins University Press.

Greimas, J. A., \& Porter, C. (1977). Elements of a narrative grammar. Diacritics, 7(1), 23-40. Baltimore: The Johns Hopkins University Press.

Jung, G. C. (1991). The concept of collective unconscious. The archetypes and the collective unconscious. (2nd ed.). New York \& London: Routledge.

Le Guin, K. U. (1969). The left hand of darkness. New York: Ace Books.

Le Guin, K. U. (1990). Dancing at the edge of the world. New York: Harper \& Row Publishers.

Le Guin, K. U. (1992). The language of the night: Essays on fantasy and science fiction. New York: Harper Collins Publishers.

Zoran, G. (1984). Towards a theory of space in narrative. Poetics Today, 5(2), 309-335. The Construction of Reality in Fiction. Durham: Duke University Press.

LONG, D. Y. (2014). 空间叙事研究 (Study of spatial narrative). Beijing: 三联书店. 